University of South Florida

DIGITAL COMMONS

@ UNIVERSITY OF SOUTH FLORIDA
Digital Commons @ University of South Florida

$5-1-2004$

\title{
Ridership Biases and Allocation of Transit Formula Grants
}

CUTR

Follow this and additional works at: https://digitalcommons.usf.edu/cutr_nctr

\section{Scholar Commons Citation}

CUTR, "Ridership Biases and Allocation of Transit Formula Grants" (2004). Research Reports. 245.

https://digitalcommons.usf.edu/cutr_nctr/245

This Technical Report is brought to you for free and open access by the National Center for Transit Research (NCTR) Archive (2000-2020) at Digital Commons @ University of South Florida. It has been accepted for inclusion in Research Reports by an authorized administrator of Digital Commons @ University of South Florida. For more information, please contact digitalcommons@usf.edu. 


\title{
RIDERSHIP BIASES AND ALLOCATION OF TRANSIT FORMULA GRANTS
}

\author{
Center for Urban \\ Transportation Research \\ University of South Florida, Tampa \\ May 2004
}

National Center for Transit Research

National Center for Transit Research Center for Urban Transportation Research University of South Florida

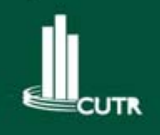




\begin{tabular}{|c|c|c|c|}
\hline $\begin{array}{l}\text { 1. Report No. } \\
\text { NCTR-575-011 }\end{array}$ & 2. Government Accession No. & \multicolumn{2}{|c|}{ 3. Recipient's Catalog No. } \\
\hline \multirow{2}{*}{\multicolumn{2}{|c|}{$\begin{array}{l}\text { 4. Title and Subtitle } \\
\text { Ridership Biases and Allocation of Transit Formula Grants }\end{array}$}} & \multicolumn{2}{|l|}{$\begin{array}{l}\text { 5. Report Date } \\
\text { May } 2004\end{array}$} \\
\hline & & \multicolumn{2}{|c|}{ 6. Performing Organization Code } \\
\hline \multicolumn{2}{|l|}{$\begin{array}{l}\text { 7. Author(s) } \\
\text { Xuehao Chu } \\
\text { xchu@cutr.usf.edu; 813-974-9831 }\end{array}$} & \multicolumn{2}{|c|}{ 8. Performing Organization Report No. } \\
\hline \multirow{2}{*}{\multicolumn{2}{|c|}{$\begin{array}{l}\text { 9. Performing Organization Name and Address } \\
\text { National Center for Transit Research (NCTR) } \\
\text { University of South Florida } \\
4202 \text { E Fowler Ave, CUT 100, Tampa, FL 33620-5375 }\end{array}$}} & \multicolumn{2}{|l|}{ 10. Work Unit No. } \\
\hline & & \multicolumn{2}{|c|}{$\begin{array}{l}\text { 11. Contract or Grant No. } \\
\text { DTRS98-G-0032 }\end{array}$} \\
\hline \multicolumn{2}{|c|}{$\begin{array}{l}\text { 12. Sponsoring Agency Name and Address } \\
\text { Office of Research and Special Programs } \\
\text { U.S. Department of Transportation, Washington, D.C. } 20590\end{array}$} & \multicolumn{2}{|c|}{ 13. Type of Report and Period Covered } \\
\hline \multicolumn{2}{|c|}{$\begin{array}{l}\text { Florida Department of Transportation } \\
605 \text { Suwannee Street, MS 26, Tallahassee, FL } 32399\end{array}$} & \multicolumn{2}{|c|}{ 14. Sponsoring Agency Code } \\
\hline \multicolumn{4}{|c|}{$\begin{array}{l}\text { 15. Supplementary Notes } \\
\text { Supported by a grant from the Florida Department of Transportation (FDOT) and the U.S. Department of } \\
\text { Transportation }\end{array}$} \\
\hline \multicolumn{4}{|c|}{$\begin{array}{l}\text { 16. Abstract } \\
\text { The paper compares unlinked passenger trips for individual agencies from } 1993 \text { through } 2001 \text { between direct counts } \\
\text { from the American Public Transportation Association and ridership reported to the National Transit Database (NTD). } \\
\text { NTD ridership can be as high as } 50 \text { percent more than direct counts, and these significant deviations exist consistently } \\
\text { over time across many agencies. While some of these deviations are attributable to undercounting in the direct counts, } \\
\text { much of them appear to be positive biases in estimated ridership that result from unintentional biases in procedures, } \\
\text { and perhaps intentional manipulation. The paper then quantitatively examines how these upward biases affect the } \\
\text { allocation of two formula grants to Florida transit agencies: the Urbanized Area Formula Grant Program at the federal } \\
\text { level and Florida's Public Transit Block Grant Program at the state level. The paper also discusses a strategy for } \\
\text { reducing these biases. }\end{array}$} \\
\hline $\begin{array}{l}\text { 17. Key Words } \\
\text { Unlinked passenger trips, passenger } \\
\text { miles, National Transit Database, } \\
\text { sampling plans }\end{array}$ & $\begin{array}{l}\text { 18. Distribution Statement } \\
\text { Available to the pub } \\
\text { (NTIS), } 5285 \text { Port R } \\
\text { through the NCTR v } \\
\text { website at http://ww }\end{array}$ & $\begin{array}{l}\text { ational Tec } \\
\text { igfield, VA } \\
\text { vww.nctr.us } \\
\text { transit/. }\end{array}$ & $\begin{array}{l}\text { lation Service } \\
\text { 487-465, } \\
\text { hrough the FDOT }\end{array}$ \\
\hline $\begin{array}{l}\text { 19. Security Classif. (of this report) } \\
\text { Unclassified }\end{array}$ & $\begin{array}{l}\text { 20. Security Classif. (of this page) } \\
\text { Unclassified }\end{array}$ & $\begin{array}{l}\text { 21. No. of pages } \\
19\end{array}$ & 22. Price \\
\hline
\end{tabular}




\section{INTRODUCTION}

Ridership is a factor in allocating transit formula grants at the federal level and in at least five states: Florida, Indiana, Iowa, New York, and Ohio. In FY 2003 the Federal program allocated about $\$ 3.5$ billion to transit agencies in urbanized areas (FTA, 2003), while the funds allocated by the transit formula grant programs in the five states total around $\$ 200$ million per year (FDOT, 2003; Jones, 2004a; IADOT, 2004; NYDOT, 2002; ODOT, 2004).

Both the formula and data inputs affect allocations. The transportation literature has focused on the formula with three themes: the use of formulas in practice, the design of formulas, and the evaluation of formulas. Carstens et al. (1976), Hartman et al. (1994), and TCRP (2004) review state practices. Design studies include Dajani and Gilbert (1978), Levine (1978), GAO (1979), Alfa and Clayton (1986), Sinha et al. (1986), and Matherly (1997).

Examples of evaluation are Miller (1979; 1980), Taylor (1991; 1995), Karlaftis and Sinha (1997), and Schmidt (2001). This paper contributes to the literature by addressing the role of data inputs. Specifically, it provides evidence on significant and widespread upward biases in ridership reported to the National Transit Database (NTD), and examines their effects on the allocation of transit formula grants.

The general literature on allocation formulas for government grants-in-aid has a history of looking at how data inputs affect allocations (e.g., USDOC, 1978; Jabine et al., 2001; Louis et al., 2002). It is widely understood that errors in formula inputs lead to unfair allocations. More important, the effects of input errors can be amplified, attenuated, or influenced in other ways when the input errors interact with the properties of a formula.

The importance of addressing input errors is also questioned. First, there is a tradeoff between increased input accuracy and the additional costs of producing these inputs. Second, accurate inputs may not be essential to achieve the goals of a formula grant program. Third, the losses are offset by the gains, so that the loss in overall social welfare resulting from these errors may be small. Fourth, correcting data errors may be less important than addressing more fundamental questions. It is suggested, for example, that what happens after the funds get to the recipient is an order of magnitude more important than marginal reduction in input errors.

However, priority should be given to three inter-related areas: 1) Minimize the very large errors in data; 2) Identify and reduce persistent biases for identifiable geographic and demographic subgroups; and 3) Guard against intentional manipulation to get grossly more allocations. One important lesson is that the data for all potential grant recipients come from the same source using the same general method. This paper contributes to this general literature by addressing the consequences of different agencies using different collection methods for formula inputs. Formula allocation procedures typically specify exactly where the input data should come from. For both the federal and Florida programs, for example, data on ridership come from the NTD. The problem is that transit agencies are allowed to use either their 100percent count or a statistical estimate through sampling for data on transit ridership regardless whether the 100-percent count is available. 
Significant and upward biases have undesirable consequences to grant allocations. First, they cloud the incentive role of ridership as an allocation factor. Transit agencies do consider the impact of changes in ridership from their actions on their share of transit formula grants. The Lee County MPO of Florida (2002), for example, considers the negative impact of raising transit fares by the local transit operator on the local share of the Urbanized Formula Grant Program because fare increases may decrease ridership. If these biases are much greater than achievable ridership growth through improved services by transit agencies, much of the incentive role of ridership in a formula is lost. Second, these biases also lead to unfair allocations that deviate from what the original formula intend. The allocation of transit formula grants to individual agencies is a zero-sum game in most cases. One agency's unfair gain is the unfair loss to other agencies.

Such biases also have undesirable consequences to the use of NTD ridership at the individual agency level for other purposes. NTD ridership, for example, is commonly used by transit agencies to compare themselves to individual peer agencies in terms of ridership per unit of services provided, ridership per unit of operating cost, or just ridership per capita. Such performance comparisons are important considerations in local decisions for transit funding. These local decisions would be seriously questioned if NTD ridership for some of the agencies involved in such performance comparisons is significantly biased upward.

The next section reviews the general transit formula programs that use ridership and common methods for collecting ridership data. The paper then compares NTD and APTA ridership numbers for three sets of transit agencies. After this comparison the paper draws the implications of unilateral ridership biases to the allocation of transit formula grants. Following the presentation of these implications, a strategy for reducing ridership biases is discussed.

\section{BACKGROUND}

\section{Techniques for Collecting Ridership Data}

Ridership appears as unlinked passenger trips or passenger miles in transit formula grant programs. While the Urbanized Area Formula Grant Program uses ridership in terms of passenger miles, all the state programs mentioned earlier use unlinked passenger trips. The following discussion focuses on fixed-route bus services.

\section{Direct Count}

A direct count of unlinked passenger trips is collected semi-automatically by fareboxes or manually by operators. A direct count may be smaller than the 100-percent count because of undercounting. As more transit operators install electronic registering fareboxes on their entire fleet, a direct count is becoming the transit industry's standard. A direct count of passenger miles is rarely available now, but will become increasingly available. With automatic passenger counters installed on an entire fleet or smart cards used systemwide by all passengers, passenger miles could also be directly counted just like unlinked passenger trips. 


\section{Statistical Estimates}

When a sampling procedure is used, a transit agency has many options to achieve the same level of statistical confidence and precision levels in the estimate. One widely used option is the FTA-approved sampling plans (UMTA, 1988). These plans have two features that appeal to transit agencies. First, they follow a simple framework. For any of the plans, the same number of one-way vehicle trips is sampled on each sample day, and the interval between sample days is constant. Second, they are assumed to have universal applicability, i.e., any transit agency can use any of the sampling plans without customizing to its conditions. Other options are often

called alternative techniques, which have two objectives in general. One is to improve sampling efficiency, i.e., reducing sample size for the same confidence and precision levels. The other one is to reduce the administrative costs of sampling. Two commonly used techniques to improve sampling efficiency are sample stratification (Smith, 1983) and ratio estimates (Furth and McCollom, 1987). One common technique to reduce administrative costs is cluster sampling (Furth et al., 1988).

\section{Transit Formula Grant Programs}

This section briefly reviews the Federal Urbanized Formula Grant Program and the Florida Public Transit Block Grant Program. Other state programs are also mentioned.

\section{Urbanized Formula Grant Program}

Part of this program provides capital, operating, and planning assistance to transit agencies in urbanized areas with populations of 200,000 or over based on a statutory formula. The allocation is based on population, population density, fixed-guideway route miles, bus and fixed-guideway vehicle revenue miles, and bus and fixed-guideway passenger miles traveled. All performance data are taken from the latest report year of the National Transit Database. Agencies may either use their 100 percent count or an estimate from a sampling procedure for annual ridership data reported to the NTD. When a direct count results in undercounting, agencies may factor up the data to account for the missing percentage (FTA, 2003). When a sampling procedure is used, a transit agency may use any sampling procedure that meets the minimum confidence level of 95 percent and the minimum precision level of \pm 10 percent.

\section{Florida Public Transit Block Grant Program}

The Florida Department of Transportation administers the Public Transit Block Grant Program as created by Section 341.052 of the Florida Statutes. This program provides state funds for capital projects and bus transit operations to providers of transit services. No single agency is apportioned more than 39 percent of the funds available, but each agency is apportioned at least $\$ 20,000$ annually. A statutory formula is used with one third of the funds available allocated on the basis of county population, revenue miles, and passengers carried, respectively. Data on revenue miles and passengers carried are for all modes combined, including purchased transportation. Data on passengers carried for this allocation come from the most recent NTD.

\section{Other State Programs}

The formulas of the other state programs differ in several ways (Hartman, et al., 1994; IADOT, 2002; NYDOT, 1999; ODOT, 2004). First, they differ in the amount of formula grants allocated using ridership. It is one-third in Florida versus 100 percent in Indiana, for example. 
Second, they differ in how ridership enters their allocation formulas. Third, they differ in the frequency of data submission and fund allocation. Almost all other programs allocate transit formula grants annually except New York, which allocates its formula grants on a quarterly basis with quarterly submission of ridership data from transit agencies. Fourth, they differ in the required statistical confidence and precision levels in ridership data. Florida requires the use of NTD data. New York requires the same statistical confidence and precision levels on an annual basis as those with the NTD but does not require the use of NTD data. Indiana has no statistical requirements on ridership data submitted from individual agencies (Jones, 2004b).

\section{RIDERSHIP BIASES}

Ridership biases for individual agencies ideally should be measured as the difference between what they report to the NTD and their 100-percent count of unlinked passenger trips. This ideal approach does not work because data are available on NTD ridership but not on the 100-percent count for individual transit agencies. This paper takes a two-step approach. The first step measures deviations in NTD ridership from a direct count for individual agencies. The second approach assesses the potential reasons for any deviations observed from the first step.

\section{Ridership Deviations}

Data on direct counts are from the American Public Transportation Association (APTA). In addition to the NTD, many transit agencies also voluntarily report monthly data on unlinked passenger trips to the APTA as a member on a quarterly basis. The APTA does not prescribe specific methods to its members for collecting these data or specific statistical confidence and precision levels (Bronson, 2003). These monthly ridership data from individual agencies form the basis for APTA's Ridership Reports (e.g., APTA, 2004) and the basis for the annual ridership in APTA's Public Transportation Fact Book (e.g., APTA, 2003). Both are widely used in the transit industry for policy debates and decision making.

Ridership deviations (NTD ridership minus APTA ridership) are assessed for three sets of transit agencies on an annual fiscal year basis. Since the NTD ridership is annual and on a fiscal year basis, the APTA monthly ridership data are converted to fiscal year data, based on the ending month of an agency's fiscal year. The first comparison is for directly-operated fixedroute bus services among 162 transit agencies in 2000. These are all agencies reporting to the NTD for 2000, for which corresponding APTA ridership data are also available. The results are summarized in Table 1 for three groups of these agencies. The NTD ridership is within one percent of the APTA ridership for the "No Deviation" group, less than the APTA ridership by more than one percent for the "Negative Deviation" group, and greater than the APTA ridership by more than one percent for the "Positive Deviation" group. A total of 57 transit agencies have a positive deviation, indicating that deviations of NTD ridership from APTA ridership are widespread. Furthermore, NTD ridership is greater than APTA ridership by 13.2 percent on average among these 57 agencies, indicating deviations of significant magnitudes.

The second comparison is for directly-operated fixed-route bus services among the largest 27 bus agencies during the period from 1993 to 2001 . These 27 bus agencies are categorized into four groups, based on their relative NTD and APTA ridership over the entire period. Among them, 5 agencies have no significant deviations in either direction; 11 with 
fluctuating deviations; 2 with negative deviations every year; and 9 with positive deviations every year. Figure 1 shows these differences in percentage terms. Again, the problem of positive deviations of NTD ridership from APTA is significant and widespread. For the group of agencies with positive deviations as a whole, the deviations average 15 percent over the entire period. The aggregate deviations of NTD ridership from APTA ridership are positive not only among the agencies with positive deviations during the period but also among the agencies with fluctuating deviations. Combined these agencies represent a total of 20 of the 27 largest bus systems. In addition, these positive deviations are consistently present over time. The aggregate deviations range annually between 12 percent and 21 percent for the group with positive deviations throughout the analysis period.

The third comparison is for all modes among Florida transit agencies from 1993 to 2001. Figure 2 shows the percent deviations for agencies that estimate NTD ridership with sampling. While not shown, deviations of NTD ridership from APTA ridership are negligible for all other Florida agencies. Agencies with large deviations, including VOTRAN, ECAT, HARTline, TalTran, and Space Coast, all use FTA-approved sampling plans. However, the deviations are far smaller for PalmTran, PSTA, and BCT even though they also use FTA-approved sampling plans. Again, the deviations are positive and significant in magnitudes in most cases.

\section{Sources of Ridership Deviations}

It is clear that positive deviations of NTD ridership from APTA ridership are significant, widespread, and consistently present over time. There are four types of potential sources that may have contributed to these deviations: APTA ridership being estimates, direct counts being undercounted, sampling errors, and non-sampling errors.

One potential complication of using APTA data as the basis for assessing biases in NTD ridership is that not all agencies report an estimate to the NTD and a direct count to the APTA. Based on conversations with them, the methods that transit agencies use to collect APTA ridership fall into three categories in relation to their NTD method: 1) Report a direct count to both entities; 2) Report an estimate to both entities using the same sample; or 3) Report an estimate to the NTD but a direct count to the APTA. In the first two cases, the two annual ridership numbers should be similar. In the third case, however, these two numbers can deviate. When the deviation is negligible, any one of these three cases is a possibility. Without knowing the specific methods that individual agencies use in obtaining either NTD or APTA ridership, these negligible deviations do not help assess biases in NTD ridership. A significant deviation, on the other hand, would most likely to indicate a direct count being reported to the APTA but an estimate to the NTD. That is, a significant deviation would indicate either significant undercounting in direct counts or upward sampling and non-sampling errors in the estimate.

A direct count is most commonly made using electronic registering fareboxes (Furth, 2000). The majority of the passengers are registered automatically as they pay their fare, and the remainder are registered manually by the operator. The synthesis by Furth (2000) indicates that operator errors in registering passengers usually have a systematic downward but small bias at the system level. If this is true, undercounting in direct counts is unlike to account for most of the observed deviations of NTD ridership from APTA ridership. 
Statistical sampling does lead to sampling errors. When sampling is done correctly, however, these sampling errors can go either direction, and over time the positive and negative errors should balance each other out. As a result, sampling errors are unlikely to account for much of the significant deviations that are widespread and consistently present over time.

Non-sampling errors can result from many sources. Sampling may be non-random. Missed random trips may be replaced with conveniently selected trips. Errors could also exist in data recording. In addition to these sampling related sources, non-sampling errors can also exist with the estimation procedure. Sample averages may be computed incorrectly. Data on the number of actually run vehicle trips may be incorrect. Institutions may also play a role. Agencies may not emphasize technical competency of their staff. The NTD process is considered by most transit agencies as a technical and financial burden (Perk and Kamp, 2003). The NTD auditing process is designed to capture anomalies, such as sudden changes over time. Consistently over-estimated ridership over time would appear normal to this auditing process. What could more likely to be caught as anomalies would be the random fluctuations in ridership resulting from sampling errors.

In general non-sampling errors from these potential sources should also fluctuate in both directions just like sampling errors. They may not be random, however, if they result from intentional manipulation or unintentional biases in procedures. Agencies have a strong incentive to not underestimate their ridership. When their execution of current procedures leads to consistent upward biases in ridership, on the other hand, agencies have a strong financial incentive to keep these procedures and to execute them as they used to.

\section{Summary}

When estimated, NTD ridership is significantly greater than direct counts reported to APTA at the individual agency level, and these positive deviations are widespread and consistently present over time. Undercounting in direct counts is like to have contributed to these deviations. However, most of these deviations appear to be attributable to non-sampling errors that have resulted from unintentional biases in procedures, and perhaps from intentional manipulation.

\section{IMPLICATIONS}

This section quantifies the effects of ridership biases on the allocations of transit formula grants. The analysis focuses on Florida, and considers both the Urbanized Formula Grant Program at the federal level and the Florida Formula Block Grant Program at the state level. The allocation formulas are first analyzed to determine the elasticity of funding allocation to individual agencies with respect to unilateral ridership biases. Dollar changes in allocation to any agency as a result of a unilateral ridership bias are then determined, using the elasticity result.

\section{Elasticity Analysis}

\section{Florida Block Grant Program}

To derive the allocation elasticity, define the following parameters: 
- $A_{i}=$ funding allocated to agency $i$,

- $A=$ total annual funding available for the Public Transit Block Grant Program,

- $P_{i}=$ annual passengers carried by agency $i$,

- $P=$ annual passengers carried by all agencies eligible with $\sum P_{i}=P$, and

- $S_{i}=P_{i} / P$ with $\sum S_{i}=1$.

The statuary formula requires that funding be allocated according to the following relationship:

$$
A_{i}=\left(\frac{A}{3}\right)\left(\frac{P_{i}}{P}\right)
$$

This allocation formula implies an allocation elasticity as follows:

$$
E_{i} \equiv \frac{\partial A_{i}}{\partial P_{i}} \frac{P_{i}}{A_{i}}=1-S_{i}
$$

which is bounded within $(0,1)$. The larger an agency is, the smaller its elasticity. The elasticity for most agencies is close to 1 . For an agency carrying $100 S_{i}$ percent of Florida's passengers, a one-percent unilateral upward bias in passengers reported would result in a $100\left(1-S_{i}\right)$ percent increase in its state funding from the Public Transit Block Grant Program.

\section{Other State Programs}

While the four other state programs all use ridership in allocating some of their transit formula grants, they differ from the Florida program in their allocation elasticity with respect to biases in ridership because ridership enters their formulas differently.

Indiana: The Public Mass Transportation Fund divides annual total funds among five groups of transit agencies with fixed proportions, and within each group allocates one-third to individual agencies based on the ratio of each agency's per capita ridership multiplied by its locally derived income over the same quantity for the entire group, and another one-third based on the ratio of each agency's ridership per vehicle revenue mile multiplied by its locally derived income over the same quantity for the entire group (Hartman et al., 1994). The allocation elasticity under this formula also takes the form in equation (2), with $S_{i}$ measured within the group to which agency $i$ belongs.

Iowa: The State Transit Assistance Program allocates one-quarter of total formula funds to urban transit agencies based on each agency's ridership per unit of operating cost relative to the sum of this ratio across all urban agencies (IADOT, 2002). Let $C_{i}$ be the ratio of ridership per unit of operating cost for agency $i$ to the sum of ridership per unit of operating cost across all urban agencies. The allocation elasticity for its urban program also takes the form in equation (2) with $S_{i}$ replaced by $C_{i}$. The more cost-effective an agency is, the smaller its elasticity. This elasticity is bounded within [1- $\left.C_{\max }, 1-C_{\min }\right]$, where $C_{\max }$ and $C_{\min }$ are the maximum and minimum of all $C_{i}$ ratios. 
New York: The State Mass Transportation Operating Assistance Program allocates formula funds to small systems based on fixed amounts per vehicle revenue mile and per passenger mile on a quarterly basis (NYDOT, 2004). The recent fixed rate per passenger, for example, has been $\$ 0.405$. With this formula, the allocation elasticity is constant at 1 .

Ohio: The Ohio Public Transportation Grant Program allocates one-fifth of the total funds to transit agencies based on each agency's share of ridership and another one-fifth based on a ratio $V_{i}$, defined as ridership per vehicle revenue mile for agency $i$ relative to the sum of ridership per vehicle revenue mile for all transit systems (ODOT, 2004). Its allocation elasticity is given by the average of $\left(1-S_{i}\right)$ and $\left(1-V_{i}\right)$ with $S_{i}$ and $V_{i}$ as the weights, or

$$
E_{i}=\frac{S_{i}\left(1-S_{i}\right)+V_{i}\left(1-V_{i}\right)}{S_{i}+V_{i}}
$$

How the size of an agency $\left(S_{i}\right)$ or its service effectiveness $\left(V_{i}\right)$ affects its elasticity is more complicated than the cases described above. However, this elasticity still is bounded within $(0,1)$ as long as all $V_{i}$ ratios are no greater than 1 .

\section{Urbanized Formula Grant Program}

This analysis focuses on the bus incentive portion, which is apportioned on the basis of passenger miles weighted by passenger miles per unit of operating cost (FTA, 2003). Also, this bus incentive portion represents 5.57 percent of the Urbanized Area Formula Program, which is $\$ 2,997,316,081$ for FY 2001. Similar to the Florida program, the following are defined:

- $F_{i}=$ funding allocated to agency $i$,

- $F=\sum F_{i}$

- $M_{i}=$ annual passenger miles on directly-operated fixed-route bus services for agency $i$,

- $O_{i}=$ operating costs of directly-operated fixed-route bus services for agency $i$, and

- $Z_{i}=M_{i} / \Sigma M_{j}$.

The statuary formula requires that the funds be allocated according to either one of the following two equivalent relationships. One formula is:

$$
F_{i}=F\left[\frac{M_{i}\left(\frac{M_{i}}{O_{i}}\right)}{\sum_{j} M_{j}\left(\frac{\sum_{j} M_{j}}{\sum_{j} O_{j}}\right)}\right]
$$

This is based on the national distribution of passenger miles weighted by passenger miles per unit of operating cost. That is, how much funding a single agency gets is proportional to its national share of passenger miles weighted by passenger miles per unit of operating cost. This proportion is given by the bracket on the right hand side of equation (4). The other formula is: 


$$
F_{i}=\left[M_{i}\left(\frac{M_{i}}{O_{i}}\right)\right]\left[\frac{F}{\sum_{j} M_{j}\left(\frac{\sum_{j} M_{j}}{\sum_{j} O_{j}}\right)}\right]
$$

This is based on the dollar unit value given by the second bracket on the right hand side of equation (5). This dollar unit value gives the amount of total funding allocated to each unit of passenger mile weighted by passenger miles per unit of operating cost. The funding to a single agency is determined by the product of this dollar unit value by its passenger miles weighted by passenger miles per unit of operating cost. This unit value is $\$ 0.00490633$ for FY2001.

Either allocation formula implies an allocation elasticity as follows:

$$
E_{i}=\frac{\partial F_{i}}{\partial M_{i}} \frac{M_{i}}{F_{i}}=2\left(1-Z_{i}\right)
$$

which is bounded within $(0,2)$. The larger an agency is, the smaller its elasticity. It is close to 2 for most agencies. For an agency carrying $100 Z_{i}$ percent of passenger miles among all eligible agencies, a one-percent upward bias in its passenger miles carried would result in a $200\left(1-Z_{i}\right)$ percent increase in federal funding from the bus incentive portion of the Urbanized Area Formula Program. The elasticity is $1.98,1.90,1.80$, and 1.60 for agencies representing 1 percent, 5 percent, 10 percent, and 20 percent of nationwide passenger miles, respectively.

\section{Allocation Analysis}

For Florida transit agencies for which FY 2001 data are available, this section illustrates increases in an agency's ridership-based allocations from both the federal and state programs that result from a unilateral upward bias in reported ridership. For the Florida Public Transit Formula Grant Program, the illustrative unilateral bias is 10 percent in the number of unlinked passenger trips for all modes. The allocation does not consider the 39 percent upper limit or the $\$ 20,000$ lower limit mentioned earlier. For the Urbanized Formula Grant Program, the illustrative unilateral bias is also 10 percent but in the amount of passenger miles for directly operated fixed-route bus services. Table 2 summarizes the results for individual agencies. A unilateral 10 percent bias in ridership would mean an increase ranging from 9.5 percent for the Miami-Dade Transit Authority to 14.2 percent for the Sarasota County Transportation Authority in combined state and Federal incentive formula grants. These increases in grant allocations can represent a strong incentive for transit agencies to report biased ridership. 


\section{STRATEGY}

An effective long-term strategy for reducing the observed ridership biases would be to require the use of the 100-percent count of unlinked passenger trips for all reporting purposes. Many transit agencies use a direct count of unlinked passenger trips for all internal purposes, but use sampling techniques for estimating both unlinked passenger trips and passenger miles for transit formula grant programs. In addition to potential ridership biases, another problem with this practice is the inconsistent numbers in unlinked passenger trips between annual reporting to formula grant programs and other reporting purposes.

Requiring the use of the 100-percent count also gives transit agencies an incentive to improve their accuracy in direct counts. Improving the estimation of an agency's ridership that has been consistently biased upward leads to lower allocations of transit formula grants to that agency. Improving the accuracy of direct counts, in contrast, leads to higher reported ridership and higher allocations as a result.

Requiring the use of the 100-percent count may also encourage transit agencies to estimate passenger miles as the product of the 100-percent count of unlinked passenger trips with an estimated average passenger trip length through alternative sampling techniques. Many agencies report a direct count of unlinked passenger trips to all reporting entities but still use FTA-approved sampling plans for estimating passenger miles. The problem with this practice is the inconsistency between annual unlinked passenger trips and passenger miles and the implied average passenger trip length. Some agencies are already using this average trip length approach to estimating passenger miles but are still using FTA-approved sampling plans. Alternative techniques are available that should require much smaller sample sizes in general and still meet FTA’s minimum confidence and precision levels (Chu, 2004).

One concern for requiring transit agencies to report their 100-percent count is how allocations may change within a state. In terms of Florida's Program, the five agencies using FTA-approved sampling plans for estimating unlinked passenger trips and reporting positively biased ridership would lose $\$ 357,000$ for FY2004. This would represent a loss of about 7.9 percent of what they would receive without this change. In contrast, all other Florida agencies would collectively gain the same amount, representing an average gain of 2.5 percent.

A far more significant concern of adopting this strategy is its potential negative impact on a state. In terms of the Federal program, for example, Florida would lose \$307,352 for FY2004 if it adopts the strategy alone. This loss of federal funding would represent about 3.8 percent of what Florida would receive without adopting the strategy. Over time, this loss is likely to be smaller as more and more agencies across the country are switching or considering switching to using a direct count to report as NTD ridership. Furthermore, any such loss is likely to be offset to some degree by savings in sampling costs from using more efficient sampling techniques based on passenger trip length. This is a real concern, however. For this long term strategy to be truly effective, the Federal Transit Administration must adopt it nationwide, and at the same time reduces the reporting burden on transit agencies. In the interim, states that use ridership in their transit formula grants should investigate other strategies to reduce the negative impacts of ridership biases on the fair allocation of their formula grants. 


\section{CONCLUSIONS}

It is clear that NTD ridership estimated from sampling is significantly greater than direct counts for many transit agencies over a number of years. While some of these differences are attributable to undercounting in the direct counts, much of them appear to be positive biases in NTD ridership that may have resulted from unintentional biases in procedures, and perhaps intentional manipulation. Through the grant allocation formulas, especially the formula in the Urbanized Formula Grant Program, these ridership biases represent strong financial incentives for them to be maintained. These ridership biases can significantly increase an agency's share of the portion of a transit formula grant program that involves ridership. The allocation of transit formula grants to individual agencies is a zero-sum game in most cases. One agency’s unfair gain is the unfair loss to other agencies.

These results support a change of policy related to reporting ridership to the National Transit Database. The current policy gives transit agencies the option of either reporting an estimate from sampling or their 100-percent count, regardless whether the 100-percent count is available. The policy should be changed to require all transit agencies to report a 100-percent count both at the Federal level and at the state level when there is a state transit formula grant program. Exclusive of any impact on grant allocations, there is little cost to this policy change. Most agencies already report a direct count to other entities, including their governing boards and the American Public Transportation Association. If they have not already, more transit agencies are switching and considering switching to electronic registering fareboxes.

This policy change has several benefits. It will result in consistent numbers in unlinked passenger trips being reported to formula grant programs and to other entities. It will give an incentive to transit agencies to improve the accuracy of their direct counts. It will also enable transit agencies to sample more efficiently for estimating passenger miles by multiplying their 100 -percent count of unlinked passenger trips and average passenger trip length.

The paper also points to several areas of research needs.

- One shortcoming of this paper is the lack of empirical data on the extent to which direct counts reported to the APTA are undercounted. There is a need to better understand the extent of undercounting in direct counts reported to both APTA and NTD.

- Another shortcoming of this paper is to pinpoint specific non-sampling errors that have contributed to the biases in ridership reported to the NTD. It is difficult for a researcher to find out the exact sources of non-sampling errors for any particular agency. If done on purpose, agencies are likely to avoid a direct answer when asked. Otherwise, poor record-keeping and staff turnover also prevent the researcher from conclusively identifying the sources.

- There is a need to understand why APTA ridership tends to be smaller at the individual agency level but greater at the national level. As this paper clearly shows, APTA ridership for directly-operated fixed-route bus services is smaller than NTD ridership with significant magnitudes consistently present over time for many transit agencies. Figure 3, on the other hand, indicates that APTA ridership for motor bus services at the national level is consistently greater than NTD ridership from 1996 through 2001. 
- Some of the grant allocation formulas lead to smaller incentives to transit agencies that are more effective in serving their residents per unit of services provided or per unit of cost. It seems to be desirable for allocation formulas to have the opposite effects. There is a need to design allocation formulas that provide larger incentives to transit agencies that are more service effective or cost-effective.

\section{ACKNOWLEDGMENT}

The Florida Department of Transportation (FDOT) provided funding through the National Center for Transit Research. Tara Bartee is the FDOT Project Manager. Christian Senn compiled the APTA ridership data. Terry Bronson provided electronic data on APA ridership for calendar years 1999-2001. The paper has benefited from comments provided by and discussions with Victoria Perk and Steve Polzin.

\section{REFERENCES}

Alfa, AS, and D Clayton (1986), An Improved Procedure for Allocating Public Transit Operating Subsidies in Canada, Journal of Advanced Transportation, 20(3), pp. 223-238.

APTA (2003), 2003 Public Transportation Fact Book, Washington, D.C.

APTA (2004), APTA Ridership Report: Third Quarter 2003, http://www.apta.com/research/stats/ridershp/index.cfm, accessed February 2004.

Boyle, Daniel K (1998), Passenger Counting Technologies and Procedures, TCRP Synthesis 29, Washington, D.C., Transportation Research Board.

Bronson, Terry (2003), e-mail communication.

Carstens, RL, CR, Mercier, and EJ Kannel (1976), Current Status of State-Level Support for Transit, Transportation Research Record, 589, pp. 14-19.

Chu, Xuehao (2004), You Can Do Better with Your Own Sampling Plans than with the FTA Plans: A Guide to the Development of Your Own Sampling Plans to Obtain Fixed-Route Bus Passenger Miles Data for the National Transit Database, Center for Urban Transportation Research, Tampa, Florida.

Dajani, Jarir S, and Gorman Gilbert (1978), Measuring the Performance of Transit Systems, Transportation Planning and Technology, 4, pp. 97-103.

FTA (2003), National Transit Database 2003 Reporting Manual, U.S. Department of Transportation, http://www.ntdprogram.com/NTD/ntdhome.nsf/?Open.

Florida Department of Transportation (FDOT) (2003), 2002 Program Objectives and Accomplishments, Office of Management and Budget. 
Furth, Peter G (2000), Data Analysis for Bus Planning and Monitoring, TCRP Synthesis 34, Washington, D.C., Transportation Research Board.

Furth, Peter G., and Brian McCollom (1987), Using Conversion Factors to Lower Transit Data Collection Costs, Transportation Research Record, 1144: 1-6.

Furth, Peter G., Keith L. Killough, and Gary F. Ruprecht (1988), Cluster Sampling Techniques for Estimating Transit Patronage, Transportation Research Record, 1165: 105-114.

General Accounting Office (GAO) (1979), Analysis of the Allocation Formula for Federal Mass Transit Subsidies, Washington, D.C.

Hartman, RJ, EM Kurtz, and AB Winn (1994), The Role of Performance-Based Measures in Allocating Funding for Transit Operations, TCRP Synthesis of Transit Practice, 6, Transportation Research Board.

Iowa Department of Transportation (IADOT) (2002), Iowa State Transit Assistance Formula Allocation, http://www.iatransit.com/regulations/sta_committee/current_sta.pdf.

IADOT (2004), Revised STA Projections for FY 2004, accessed on February 25, 2004. http://www.iatransit.com/history/sta_information/revised_fy04_STA_1-7-04.xls.

Jabine, Thomas B., Thomas A. Louis, and Allen L. Schirm (2001), Choosing the Right Formula, Washington, D.C., National Research Council.

Jones, Brian (2004a), Excel file via e-mail on total formula funds allocated through the Indiana Public Mass Transportation Fund since 1986.

Jones, Brian (2004b), e-mail communication.

Karlaftis, MG; Sinha, KC (1997), Performance-Based Transit Operating Subsidy Allocation: A Before and After Study, Journal of Public Transportation, 1(2), pp. 1-23.

Lee County MPO (2002), Long-Term Options for Funding Transit and Transportation Disadvantaged Services in Lee County-FINAL REPORT, North Fort Myers, Florida.

Levine, HA (1978), Using Efficiency Incentives to Allocate Transit-Operating Deficits, Traffic Quarterly, 32(1), pp. 87-104.

Louis, TA, TB Jabine, and MA Gerstein (2002), Statistical Issues in Allocating Funds by Formula, Washington, D.C., National Research Council.

Matherly, D (1997), Developing a Performance-Based Transit Allocation Formula: Case Study for a Participatory Process, Transportation Research Record, 1604, pp. 83-91.

Miller, James H (1979), An Evaluation of Allocation Methodologies for Public Transportation 
Operating Assistance, Transportation Journal, 19 (1), pp. 40-49.

Miller, JH (1980), Use of Performance-Based Methodologies for The Allocation of Transit Operating Funds, Traffic Quarterly, 34(4), pp. 555-574.

New York Department of Transportation (NYDOT) (1999), Rules and Regulations Part 975, Statewide Mass Transportation Operating Assistance Program.

NYDOT (2002), 2001 Annual Report on Public Transportation Assistance Programs in New York State, Passenger Transportation Division, http://www.dot.state.ny.us/pubtrans/annual/2001annual2.html.

Ohio Department of Transportation (ODOT) (2004), 2004 Ohio Public Transportation Grant Program (OPTGP) - Formula Criteria, accessed February 2004. http://www.dot.state.oh.us/ptrans/downloads/2004\%20Formula\%20Criteria\%20final.doc.

Perk, Victoria, and Nign Kampa (2003), Handbook of Automated Data Collection Methods for the National Transit Database, Center for Urban Transportation Research, Tampa, Florida.

Schmidt, S (2001), Incentive Effects of Expanding Federal Mass Transit Formula Grants, Industrial and Labor Relations Review, 20(2), pp. 239-261.

Sinha, KC, JN Parsons, DT Barnum, and EA Sharaf (1986), Development and Implementation of a Performance-Based State Transit Subsidy Allocation Formula for Indiana, Transportation Research Record, 1076, pp. 30-38.

Smith, Robert L., Jr. (1983), Innovation and Incremental Improvement in Bus Transit Passenger Data Collection, Washington, D.C., U.S. Department of Transportation.

Taylor, BD (1991), Unjust Equity: An Examination of California's Transportation Development Act, Transportation Research Record, 1297: pp 85-92.

Taylor, BD (1995), Program Performance versus Transit Performance: Explanation for Ineffectiveness of Performance-Based Transit Subsidy Programs, Transportation Research Record, 1496, pp. 43-51.

TCRP (2004), A Status Report on the Use of Performance-Based Measures in Allocating Transit Funding, Transit Cooperative Research Program, Transportation Research Board.

Urban Mass Transportation Administration (UMTA) (1988), Sampling Procedures for Obtaining Fixed Route Bus Operating Data Under the Section 15 Reporting System, Circular UMTA-C-2710.1A, U.S. Department of Transportation.

US Department of Commerce (USDOC) (1978), Report on Statistics for Allocation of Funds, Statistical Policy Working Paper 1, Washington, D.C. 
Table 1. Differences in NTD and APTA Ridership for 162 Agencies in FY 2000

\begin{tabular}{|l|r|r|r|r|r|}
\hline Groups & $\begin{array}{r}\text { APTA } \\
(000 s)\end{array}$ & $\begin{array}{r}\text { NTD } \\
(000)\end{array}$ & $\begin{array}{r}\text { NTD-APTA } \\
(000 s)\end{array}$ & $\begin{array}{r}\text { 100(NTD-APTA)/APTA } \\
(\%)\end{array}$ & $\begin{array}{r}\text { Number of } \\
\text { Agencies }\end{array}$ \\
\hline No Deviation & $1,468,774$ & $1,468,105$ & -669 & 0.0 & 74 \\
\hline Negative Deviation & 821,272 & 778,845 & $-42,427$ & -5.2 & 31 \\
\hline Positive Deviation & $1,645,828$ & $1,863,408$ & 217,580 & 13.2 & 57 \\
\hline All & $3,935,874$ & $4,110,358$ & 174,484 & 4.4 & 162 \\
\hline
\end{tabular}

Sources: Excel files of member agencies reported ridership to APTA for calendar years 1999-2001 from APTA's Terry Bronson and an Excel file of ridership for individual agencies from the NTD website for fiscal year 2000. Ridership data are limited to directly-operated fixed-route bus services. 
Table 2. Total Allocated State and Federal Incentive Grants and Added Funds from Hypothetical Unilateral 10\% Upward Biases in Ridership for Florida Transit Agencies, FY 2004

\begin{tabular}{|l|r|r|r|}
\hline \multirow{2}{*}{ Agencies } & Base Allocation of State \& & \multicolumn{2}{|c|}{ Added Funds from 10\% Bias } \\
\cline { 3 - 4 } & Federal Incentive Grants & Amount & $\begin{array}{r}\% \text { of Base } \\
\text { Allocation }\end{array}$ \\
\hline Manatee County Area Transit & $\$ 93,583$ & $\$ 10,641$ & 11.4 \\
\hline Pinellas Suncoast Transit Authority & $\$ 1,193,306$ & $\$ 145,581$ & 12.2 \\
\hline Lee County Transit & $\$ 337,367$ & $\$ 44,833$ & 13.3 \\
\hline Broward County Mass Transit Division & $\$ 4,714,308$ & $\$ 593,086$ & 12.6 \\
\hline Gainesville Regional Transit System & $\$ 728,852$ & $\$ 85,401$ & 11.7 \\
\hline Lakeland Area Mass Transit District & $\$ 183,088$ & $\$ 22,549$ & 12.3 \\
\hline County of Volusia dba: VOTRAN & $\$ 551,743$ & $\$ 71,072$ & 12.9 \\
\hline Miami-Dade Transit & $\$ 10,525,649$ & $\$ 1,000,632$ & 9.5 \\
\hline Central Florida Regional Transportation Authority & $\$ 3,481,763$ & $\$ 466,118$ & 13.4 \\
\hline City of Tallahassee-TALTRAN & $\$ 432,736$ & $\$ 49,057$ & 11.3 \\
\hline Palm Tran, Inc. & $\$ 824,588$ & $\$ 104,902$ & 12.7 \\
\hline Escambia County Area Transit & $\$ 193,394$ & $\$ 24,225$ & 12.5 \\
\hline Jacksonville Transportation Authority & $\$ 1,320,319$ & $\$ 174,864$ & 13.2 \\
\hline Hillsborough Area Regional Transit Authority & $\$ 1,226,014$ & $\$ 150,087$ & 12.2 \\
\hline Sarasota County Transportation Authority & $\$ 295,832$ & $\$ 42,131$ & 14.2 \\
\hline Space Coast Area Transit & $\$ 106,223$ & $\$ 11,788$ & 11.1 \\
\hline Pasco County Public Transportation & $\$ 39,588$ & $\$ 4,700$ & 11.9 \\
\hline Bay County Council On Aging & $\$ 24,174$ & $\$ 2,491$ & 10.3 \\
\hline Indian River County Council on Aging, Inc. & $\$ 37,852$ & $\$ 3,821$ & 10.1 \\
\hline Polk County Transit Services Division & $\$ 17,234$ & $\$ 1,744$ & 10.1 \\
\hline
\end{tabular}

Notes: The 10 percent upward biases are hypothetical for illustration purposes. For any given agency, the added funds only reflect the impacts of a 10-percent upward bias in its reported ridership on its only grant allocations. The impacts of a 10-percent upward bias in any one agency's reported ridership on other agencies' grant allocations are not included.

Sources: Computed using FY 2001 data on unlinked passenger trips, passenger miles, and operating costs and using FY 2004 data on available funding. 
Figure 1. Percent Deviations in Directly-Operated Fixed-Route Bus Services for Largest 27 Bus Systems by Group

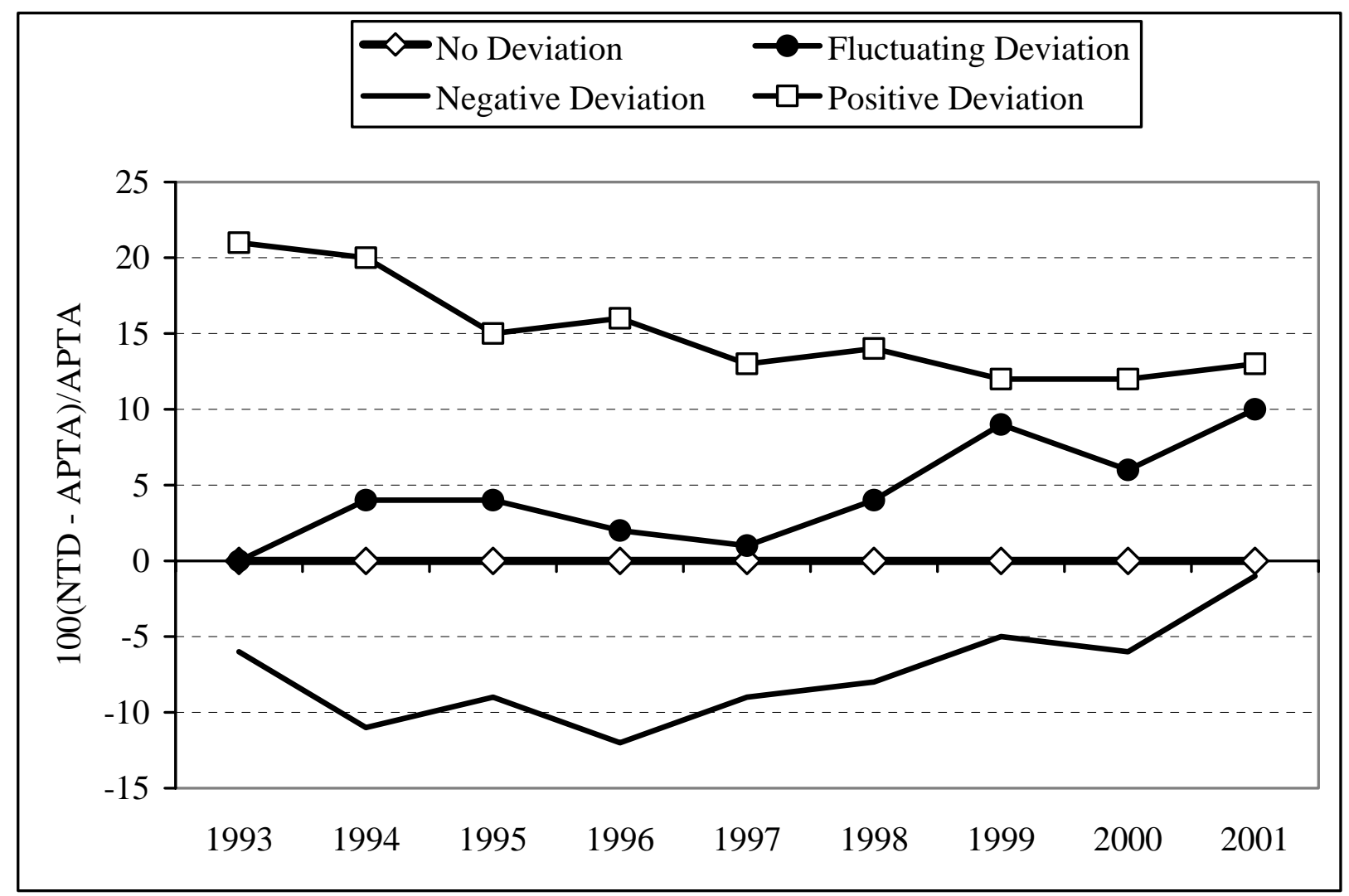

Notes: The number of agencies within each group: No Deviation = 5; Fluctuating Deviation = 11; Negative Deviation $=2$; and Positive Deviation $=9$.

Sources: APTA ridership data are from the quarterly APTA Transit Ridership Reports from the relevant years. NTD ridership data are from the annual Data Tables. The largest bus systems are based on those listed in APTA's Transit Ridership Reports for Largest Bus Systems. 
Figure 2. Percent Deviations in Total Ridership for Florida Transit Systems

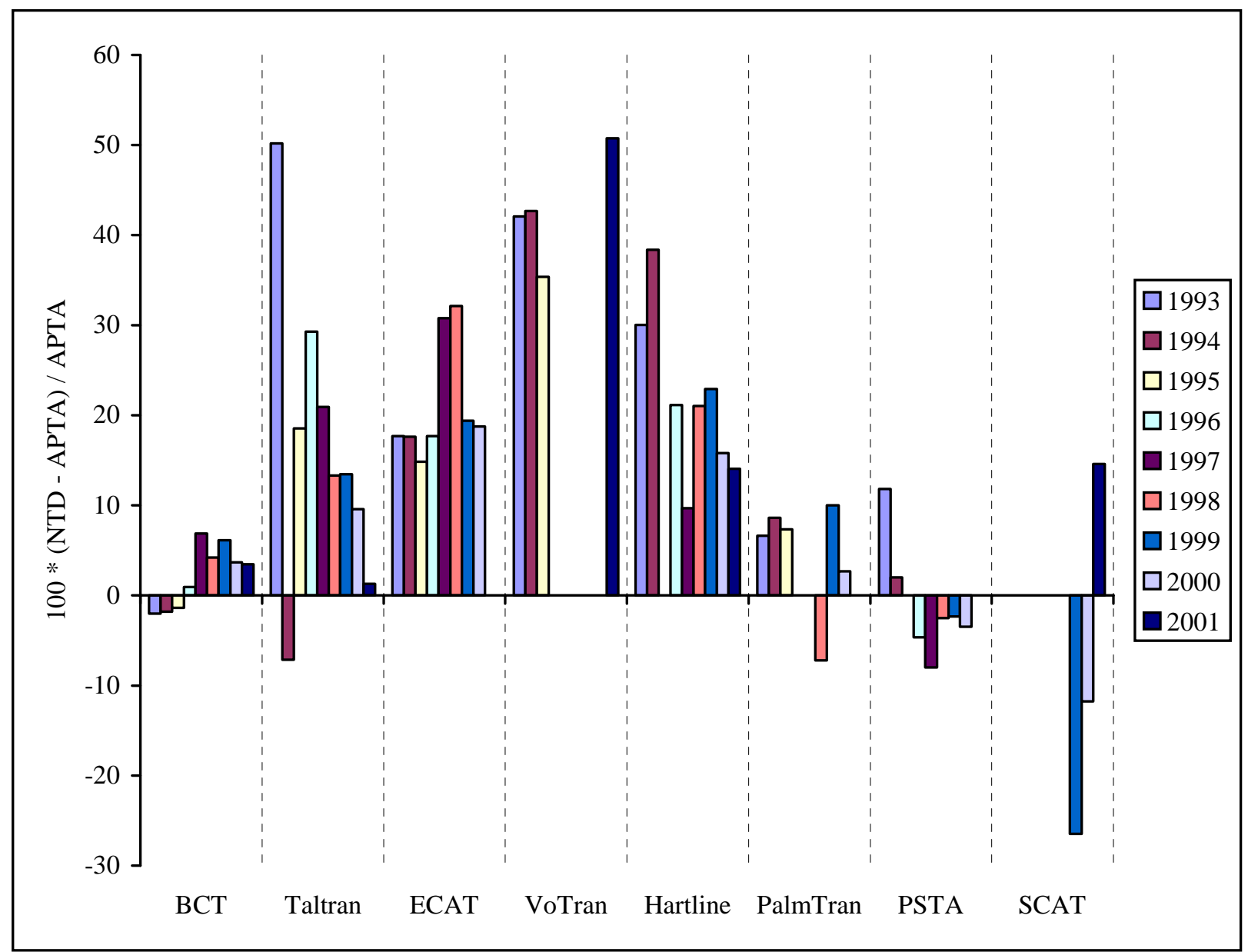

Notes: The bars from the left to the right for a given agency follow the temporal order of the fiscal years 1993 through 2001. An absence of bars indicates missing data. These operators are:

BCT $=$ Broward County Mass Transit Division

TalTran = City of Tallahassee-TALTRAN

ECAT $=$ Escambia County Area Transit

VoTran = County of Volusia

Harline = borough Area Regional Transit Authority

PalmTran = Palm Tran, Inc.

PSTA = Pinellas Suncoast Transit Authority

SCAT $=$ Space Coast Area Transit

Sources: APTA ridership data are from the quarterly APTA Transit Ridership Reports from the relevant years. NTD ridership data are from the annual Data Tables. 
Figure 3. National NTD and APTA Ridership and Percent Deviations for Motor Buses

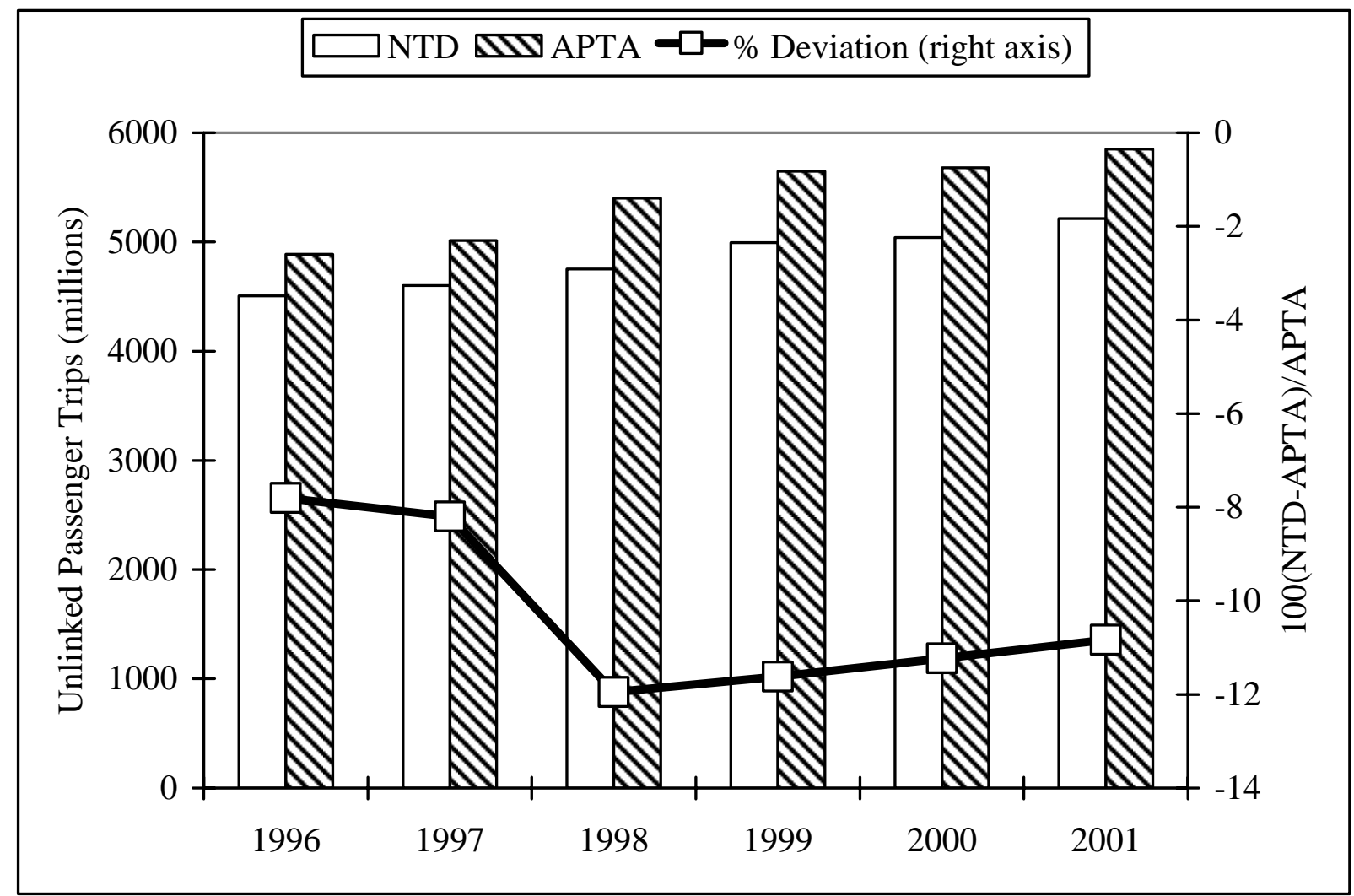

Sources: APTA ridership data are from Table 5, Unlinked Passenger Trips by Mode, Millions at http://www.apta.com/research/stats/ridershp/trips.cfm. NTD ridership data are from the annual Data Tables. 